\title{
Perception of Health Care Professionals (HCPs) on Telemedicine in India
}

\author{
Arun Kumar S, Ankita Wadhwa, Gramle Amol
}

\begin{abstract}
With a nationwide lockdown imposed, there was a substantial drop in the in-clinic patient visits in 2020. Telemedicine gained momentum during the pandemic and virtual modes of teleconsultation were adopted by the health care professionals. A PAN India research survey was carried out to understand the HCP perspective on virtual consultation, 'Telemedicine'. The survey aims to assess the behavioral shift in HCPs from face-to-face to adapting Telemedicine in clinical practice post-pandemic and foreseeing the future of Teleconsultation for Health Care Professionals in India. A PAN India survey was conducted among 154 participants. The questions were based on Telemedicine as a practice, barriers and influential factors for Telemedicine \& the significance of guidelines published by the Telemedicine Society of India (TSI) in clinical practice. The survey included varied forms for the questions such as Multiple choice, Likert scale and Polar Questions. Descriptive statistics were used to analyze the outcomes of this research which will help to identify the influential factors in the uptake of Telemedicine practice by the HCPs and how the Telemedicine Society of India could help them with the guidelines. This research will further uncover the challenges faced by the HCPs during Telemedicine consultation in the post-Covid era, and identify potential platforms for teleconsultation, in a virtual environment.
\end{abstract}

Keywords: Healthcare, Online, Telemedicine, Digital, COVID-19.

\section{INTRODUCTION}

$\mathrm{W}$ ith an unprecedented event of COVID-19 Pandemic and a nationwide lockdown implemented, patients were in dilemma to go to a clinic for their ailments with the risk of infection [1]. This led to the government providing guidelines for practicing telemedicine to ensure the delivery of healthcare services to the public.

Telemedicine is defined as the delivery of medical care, by healthcare professionals (HCPs) using information or communication technology, which ensures the patient to access the healthcare services without the risk of contacting the COVID-19

Manuscript received on April 09, 2021.

Revised Manuscript received on April 14, 2021.

Manuscript published on April 30, 2021.

* Correspondence Author

Arun Kumar S*, Intern, Consulting and Solutioning BioQuest Solutions Pvt. Ltd., Bengaluru, India. Email: arun.s@bioquestglobal.com

Ankita Wadhwa, Digital Manager, Consulting and Solutioning, BioQuest Solutions Pvt. Ltd., Bengaluru, India. Email: ankita.w@bioquestglobal.com

Dr. Amol Gramle, Vice President, Consulting and Solutioning, BioQuest Solutions Pvt. Ltd., Bengaluru, India. Email: gramle.amol@bioquestglobal.com

(c) The Authors. Published by Blue Eyes Intelligence Engineering and Sciences Publication (BEIESP). This is an open access article under the CC BY-NC-ND license (http://creativecommons.org/licenses/by-nc-nd/4.0/) and reduces the burden on hospitals by churning the overcrowding in the hospitals, thereby ensuring the HCPs could provide proper care to the COVID-19 patients. This study is conducted to better understand the impact and acceptance of Telemedicine among HCPs in India.

\section{METHODS AND MATERIALS}

BioQuest Solutions Pvt. Ltd. conducted the survey to analyse the impact of telemedicine among the doctors during the impact of COVID-19.

\section{A. Questionnaire Preparation}

A Questionnaire with 11 questions was made available on google forms focusing on the challenges they face in practicing telemedicine.

3 Types of Questions were populated in the survey. First one being, the Multiple-choice questions where the HCP were asked to select a maximum of three answers from the choices provided. An additional choice was also provided where they could write their answers along with selecting from the provided choices.

The other type was Likert scale wherein the HCPs were provided with a statement followed by a range of 5 options from Strongly Agree to Strongly Disagree to be selected from. Lastly, polar questions with yes or no answers were also asked.

\section{B. Data Sample}

This survey was then shared with the HCP database available with BioQuest Solutions Pvt Ltd, who were from different specialties and had varied years of experience. The survey was open from August 2020 to December 2020 and 154 responses were collected at the end of the survey.

\section{Statistical Analysis}

To analyze the results of this study, Descriptive statistics in terms of frequency and percentage were utilized. Also, the significance between the variables and the answers of the HCPs were tested utilizing the Chi-square test. The analysis was done using Microsoft Excel and p-values less than 0.05 were considered significant.

\section{RESULTS AND DISCUSSIONS}

The survey covered 18 states and 3 Union territories namely Tamilnadu, Karnataka, West Bengal, Haryana, Maharashtra, Uttar Pradesh, Odisha, Telangana, Kerala, Andhra Pradesh, Assam, Bihar, Gujarat, Rajasthan, Jharkhand, Arunachal Pradesh, Punjab, Madhya Pradesh, Delhi, Goa and Pondicherry with a good mix of HCPs with diverse specialties such as Dermatologists,

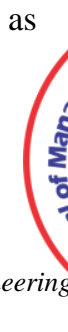

\& Sciences Publication

(C) Copyright: All rights reserved.

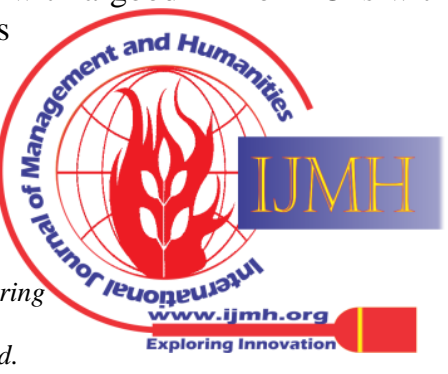


Orthopedics, Oncologists, Pediatricians, Gynecologists, Respiratory Medicine Consultants, Dentists, Intensivists, Dieticians, Chest Physicians and General Practitioners. $44.2 \%$ of the respondents had $1-2$ years of experience, $24 \%$ of the respondents had 5-10 years of experience and $31.8 \%$ of the respondents had more than 10 years of experience. $55.9 \%$ of the responding HCPs worked for a hospital, $40.1 \%$ of them owned a clinic/hospital and 3.9\% were government doctors. The findings from the survey are as follows.

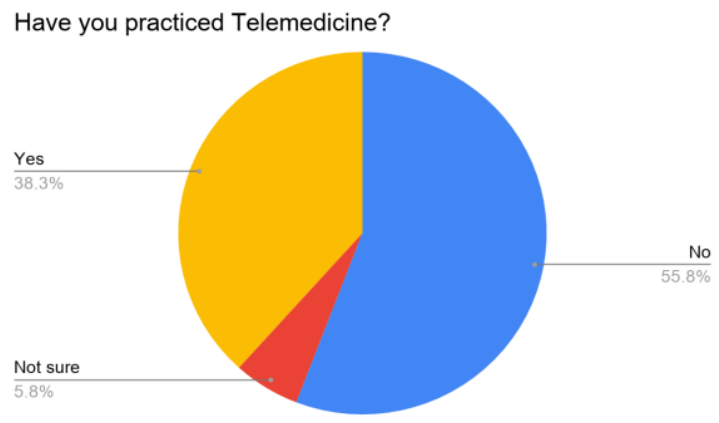

Fig.1: Practice of Telemedicine

From fig.1, Of the 154 HCPs who participated in the survey, about $55.8 \%$ of the HCPs have not practiced telemedicine yet and 5.8\% of them were not aware about the concept of Telemedicine. Only $38.3 \%$ of the HCPs have practiced Telemedicine. This shows that even though the need for Telemedicine was high during the pandemic, the HCPs were still focused on practicing offline rather than switching to online telemedicine solutions [2]

Table I - Factors (may) influence to practice telemedicine

\begin{tabular}{|l|c|c|}
\hline \multicolumn{1}{|c|}{ Factors } & $\begin{array}{c}\text { Number of } \\
\text { Responses (n) }\end{array}$ & Percentage \\
\hline Due to Covid-19 & 105 & $50.5 \%$ \\
\hline Patient's requests & 39 & $18.8 \%$ \\
\hline Legality of the guidelines & 23 & $11.1 \%$ \\
\hline $\begin{array}{l}\text { Proactive willingness to try } \\
\text { the new norms of } \\
\text { e-practice }\end{array}$ & 20 & $9.6 \%$ \\
\hline $\begin{array}{l}\text { Sustain the source of } \\
\text { income from clinical } \\
\text { practice }\end{array}$ & 18 & $8.7 \%$ \\
\hline Connectivity issues & 3 & $1.4 \%$ \\
\hline
\end{tabular}

From Table I, we could conclusively see that the factor that might make $50.5 \%$ of the HCPs practise Telemedicine is Covid-19 pandemic. Followed by the second highest factor, which is $18.8 \%$ where their patient(s) requested them to start practising telemedicine. This shows that the HCPs will adapt to telemedicine if only there is a strong demand for it [3]].

Table II - Barriers that remain with telemedicine

\begin{tabular}{|l|c|c|}
\hline \multicolumn{1}{|c|}{ Barriers } & $\begin{array}{c}\text { Number of } \\
\text { Responses (n) }\end{array}$ & Percentage \\
\hline $\begin{array}{l}\text { Lack of time to collect } \\
\text { appropriate medical history }\end{array}$ & 93 & $33.7 \%$ \\
\hline $\begin{array}{l}\text { Challenges with patient } \\
\text { counselling }\end{array}$ & 92 & $33.3 \%$ \\
\hline
\end{tabular}

\begin{tabular}{|l|c|c|}
\hline $\begin{array}{l}\text { Application of clinical } \\
\text { guidelines for screening }\end{array}$ & 27 & $17.4 \%$ \\
\hline Patient retention challenges & 48 & $9.8 \%$ \\
\hline Technical challenges & 13 & $4.7 \%$ \\
\hline Patient satisfaction & 3 & $1.1 \%$ \\
\hline
\end{tabular}

From Table II, Challenges with patient counselling and lack of time to collect appropriate medical history have equally remained as barriers for $67.4 \%$ of the HCPs. That is, HCPs feel that teleconsultation will not provide them with enough time to speak with the patients to collect appropriate medical history and provide them with proper counseling [4].

Table III - Factors that build trust in the uptake of telemedicine

\begin{tabular}{|l|c|c|}
\hline \multicolumn{1}{|c|}{ Factors } & $\begin{array}{c}\text { Number of } \\
\text { Responses (n) }\end{array}$ & Percentage \\
\hline $\begin{array}{l}\text { Provide dedicated backend } \\
\text { support for timely resolution of } \\
\text { queries }\end{array}$ & 79 & $29.9 \%$ \\
\hline $\begin{array}{l}\text { Offer tools for point of care } \\
\text { clinical practice }\end{array}$ & 71 & $26.9 \%$ \\
\hline $\begin{array}{l}\text { Promotion from State Medical } \\
\text { Councils }\end{array}$ & 53 & $20.1 \%$ \\
\hline $\begin{array}{l}\text { Guidance from Affiliated } \\
\text { Medical Associations }\end{array}$ & 31 & $11.7 \%$ \\
\hline $\begin{array}{l}\text { Make the course mandatory for } \\
\text { e-practice }\end{array}$ & 17 & $6.4 \%$ \\
\hline $\begin{array}{l}\text { Provide recommendations on } \\
\text { appropriate platforms }\end{array}$ & 8 & $1.9 \%$ \\
\hline Offer credit points & $5 \%$ & \\
\hline
\end{tabular}

From table III, about $29.9 \%$ of the HCPs wanted dedicated backend support for the resolution of queries from their end. This shows that the HCPs were not quite confident in their effective practice of Telemedicine. 20.1\% of the HCPs also felt that promotions from their respective state medical councils will also enable them to build trust to effectively uptake the practice []ㅡ.

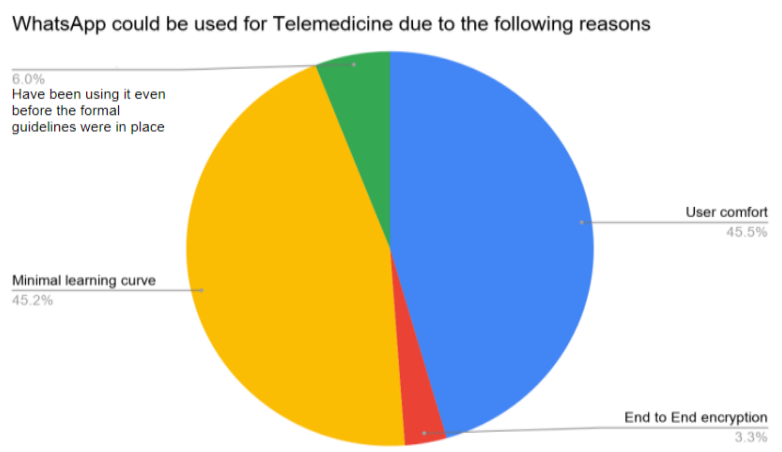

Fig.2: WhatsApp as Telemedicine platform

Blue Eyes Intelligence Engineerin

\& Sciences Publication

(C) Copyright: All rights reserved.

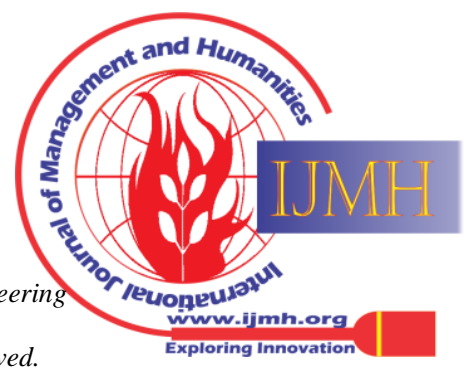


From Fig.2, when asked about WhatsApp as a telemedicine platform, $45.5 \%$ of the HCPs would prefer WhatsApp as a telemedicine platform as it offers good user comfort, $45.2 \%$ supported the minimal learning curve and 3.3\% opted for an end to end encryption enabling WhatsApp as a platform for telemedicine communication. $6 \%$ of them were already using WhatsApp to give patient counselling [6] .

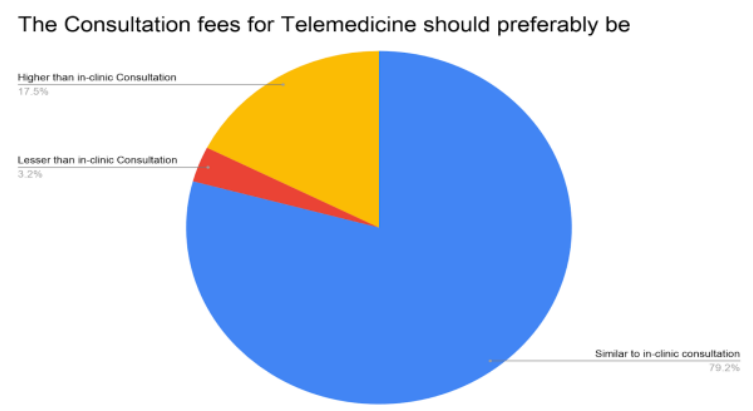

Fig.3: Consultation fee for Telemedicine

From Fig.3, when asked about the consultation fee that they would charge for telemedicine, $79.2 \%$ of the HCPs wanted whereas $17.5 \%$ felt that it should be higher than their normal charges. $3.2 \%$ of them felt that it should be lesser than the usual in-clinic fee. This suggests that the majority of the HCPs want to charge the same in-clinic consultation fee as the work of consultation remains the same whether it is online or online [?].

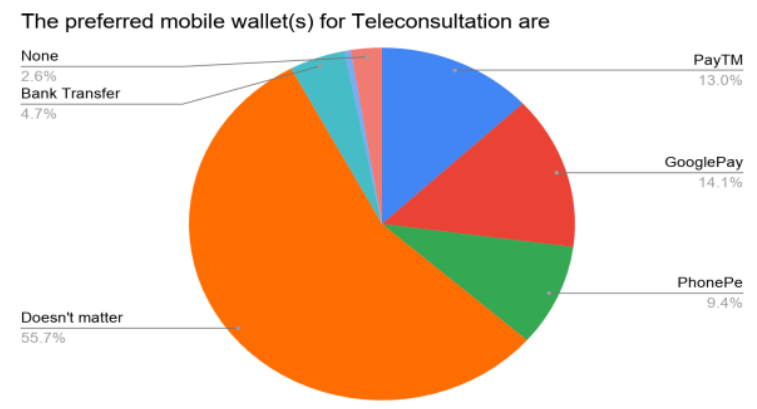

Fig.4: Preferred Mobile wallet for teleconsultation

From Fig 4, 55.7\% of the HCPs said that the wallet/service does not matter for their teleconsultation. 14.1\% of the HCPs preferred Google pay (now Gpay) as their wallet service provider for teleconsultation. From this, we could understand that the majority of HCPs were not concerned about the mobile wallet partners [] $]$.

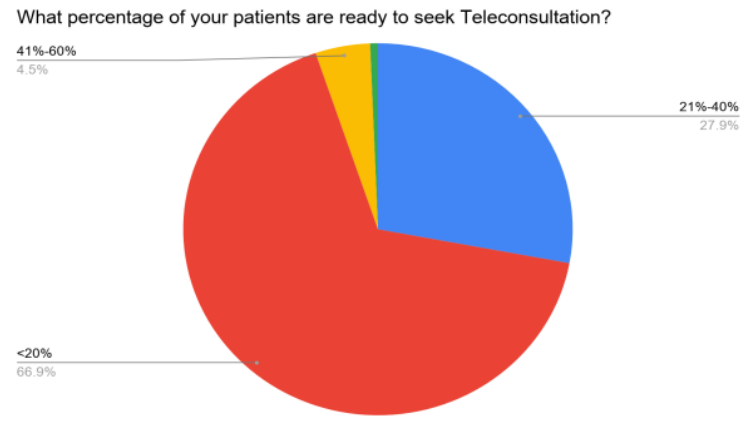

Fig.5: Patients ready to seek Teleconsultation their consultation fee to remain the same as their in-clinic fee

From Fig.5, When asked about patient's readiness to seek teleconsultation, $66.9 \%$ of the HCPs felt that only less than $20 \%$ of their existing patients will be ready to seek online consultation, followed by $27.9 \%$ of the HCPs who felt about $21 \%$ to $40 \%$ patients will be ready, while $4.5 \%$ of HCPs felt about $41 \%$ to $60 \%$ will be ready and around $0.6 \%$ HCPs stated that more than $60 \%$ of their patients will be ready to seek teleconsultation if provided to them. This shows that the majority of HCPs feel that their existing patients will not be ready to accept teleconsultation even if they provide it to them [ $\underline{9}$.

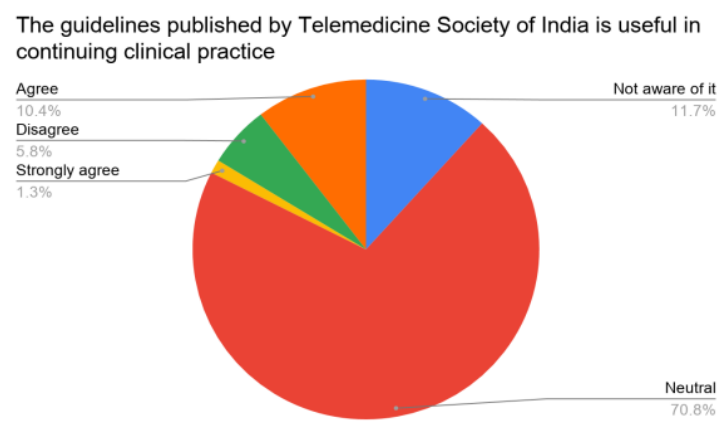

Fig.6: Opinion on published guidelines

From Fig 6, 70.8\% of the HCPs were neutral towards the guidelines published by the Telemedicine Society of India [10]. This suggests that most of the HCPs were not sure about the guidelines on the practice of telemedicine and from table $\mathrm{IV}$, they have given multiple ways to improve the current telemedicine guidelines which are discussed below.

Table IV - Opportunities to improve the current telemedicine guidelines

\begin{tabular}{|l|c|c|}
\hline \multicolumn{1}{|c|}{ Factors } & $\begin{array}{c}\text { Number of } \\
\text { Responses (n) }\end{array}$ & Percentage \\
\hline $\begin{array}{l}\text { Offering specialty-specific } \\
\text { recommendations }\end{array}$ & 69 & $37.1 \%$ \\
\hline $\begin{array}{l}\text { Including referral pathway to } \\
\text { seek attention from specialists }\end{array}$ & 54 & $29.0 \%$ \\
\hline $\begin{array}{l}\text { Partnership with respective } \\
\text { State Medical Councils }\end{array}$ & 46 & $24.7 \%$ \\
\hline $\begin{array}{l}\text { Society endorsed Telemedicine } \\
\text { practice platform }\end{array}$ & 17 & $9.1 \%$ \\
\hline
\end{tabular}

From Table IV, $37.1 \%$ of the HCPs wanted speciality-specific recommendations to better understand the stand of telemedicine in their particular specialty to improve the current telemedicine guidelines followed by $29 \%$ of them to include referral pathways where they could seek the attention of specialists who are well versed in telemedicine so that they could be able to communicate with them to properly adapt telemedicine practice and $24.7 \%$ of HCPs who wanted association or partnership from their respective state medical councils to actively help them better the telemedicine guidelines [11].

Published By:

Blue Eyes Intelligence Engineering

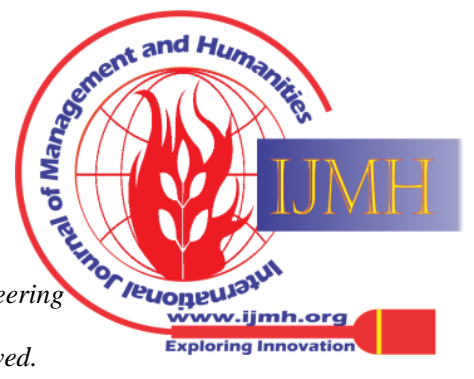




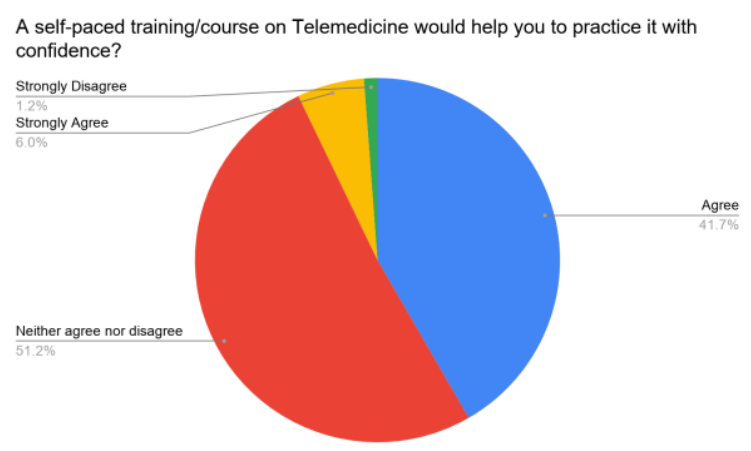

Fig.7: Training for practise of telemedicine

From Fig 7, 51.2\% of the HCPs were nonchalant about a training course on telemedicine while $47.7 \%$ of HCPs including the $6 \%$ who strongly agreed, felt that it would help them to increase the confidence in practising it and $1.2 \%$ of the HCPs strongly felt that it will not help them in the effective practice of telemedicine. From this, we could suggest an offering of a training course will help to boost the confidence of the HCPs in practising telemedicine [12].

While studying the responses based on the years of experience in practise, $50 \%$ of the HCPs who had more than 10 years of experience had practised telemedicine at some point in their life and only $37 \%$ of the HCPs who had less than 10 years of experience had practised telemedicine.

While analysing the challenges faced during practice of telemedicine, $61 \%$ of the HCPs who had more than 10 years of experience had some hardship in patient counselling and patient retention while $69 \%$ of the HCPs who had less than 10 years of experience had difficulties in lack of time to collect appropriate medical history and in patient counselling.

Also analysing the responses based on the regional demographics, $60 \%$ of the HCPs from North India had practised telemedicine followed by $40 \%$ in South India, 35\% in West India and 30\% in East India. This shows that the HCPs from the Northern regions have the most knowledge and experience with telemedicine and HCPs from the Eastern regions are less exposed to online modes of clinical practice.

The HCPs from South India were more optimistic about the potential demands of telemedicine from their patients where $45 \%$ of the HCPs feel that more than $20 \%$ of their patients will be ready to utilize telemedicine if they offer it, closely followed by 35\% from North India, 25\% from West India and the least optimistic HCPs were from Eastern India where less than $10 \%$ believed that more than $20 \%$ of their patients will be ready to utilize telemedicine.

From both experience-based analysis and region-based analysis of the responses, patient counselling via telemedicine is the region where the HCPs faced most of their concerns.

As we could observe from fig.3, a self-paced course on how to practice telemedicine effectively could help the problem of patient counselling and encourage the HCPs to confidently venture further into telemedicine.

\section{CONCLUSION}

From this research, we could conclude that the HCPs still feel challenging to provide effective patient counselling via telemedicine. This could be improved by providing them with training on do's and don'ts while practicing telemedicine and explaining to them the guidelines based on their speciality. Even with these challenges, WhatsApp has a lot of potential to be utilized for teleconsultation with its ease of use and minimal learning curve.

\section{REFERENCES}

1. Keesara S, Jonas A, Schulman K. Covid-19 and health care's digital revolution. New England Journal of Medicine. 2020 Jun 4;382(23):e82.

2. Chellaiyan VG, Nirupama AY, Taneja N. Telemedicine in India: Where do we stand?. Journal of family medicine and primary care. 2019 Jun;8(6):1872.

3. Mishra V. Factors affecting the adoption of telemedicine during COVID-19. Indian Journal of Public Health. 2020 Jun 1;64(6):234.

4. Almathami HK, Win KT, Vlahu-Gjorgievska E. Barriers and facilitators that influence telemedicine-based, real-time, online consultation at patients' homes: systematic literature review. Journal of medical Internet research. 2020;22(2):e16407.

5. Rahman M, Das S, Tazim MZ, Rana M, Tuhin RA, Das AK. State of the Art of ICT based Telemedicine and E-health Services in Bangladesh. In2021 6th International Conference on Inventive Computation Technologies (ICICT) 2021 Jan 20 (pp. 1266-1272). IEEE.

6. Jakhar DE, Kaul SU, Kaur IS. WhatsApp messenger as a teledermatology tool during coronavirus disease (COVID-19): from bedside to phone-side. Clinical and experimental dermatology. 2020 Aug;45(6):739-40

7. Ateriya N, Saraf A, Meshram VP, Setia P. Telemedicine and virtual consultation: The Indian perspective. The National medical journal of India. 2018 Jul 1;31(4):215.

8. Azietsi-Bokor WI. Acceptance and Use of Mobile Payments in Healthcare Delivery among Private Providers in the Ayawaso Municipality (Doctoral dissertation, University of Ghana).

9. Malhotra P, Ramachandran A, Chauhan R, Soni D, Garg N. Assessment of Knowledge, Perception, and Willingness of using Telemedicine among Medical and Allied Healthcare Students Studying in Private Institutions. Telehealth and Medicine Today. 2020 Nov 27.

10. Damodharan D, Narayana M, Channaveerachari NK, Math SB. Telemedicine practice guidelines of India, 2020: Implications and challenges. Indian Journal of Psychiatry. 2021 Jan 1;63(1):97.

11. Iyengar K, Jain VK, Vaishya R. Pitfalls in telemedicine consultations in the era of COVID 19 and how to avoid them. Diabetes \& Metabolic Syndrome: Clinical Research \& Reviews. 2020 Sep 1;14(5):797-9.

12. Manjunatha N, Sadh K, Shashidhara HN, Manjunatha BR, Shashank HP, Ashwatha KP, Parthasarathy R, Kumar CN, Math SB, Thirthalli J. Establishing performance indicators of telemedicine-based "On-Consultation Training" of primary care doctors: An innovation to integrate psychiatry at primary care. Indian Journal of Community Medicine. 2021 Jan 1;46(1):75.

\section{AUTHORS PROFILE}

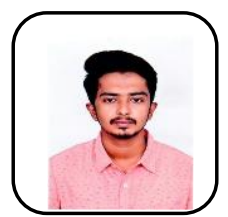

Arun Kumar S, Currently interning at BioQuest Solutions Pvt. Ltd under the Consulting and Solutioning (Pre-Sales) team. Pursuing M.Sc. Biotechnology in Vellore Institute of Technology, Vellore. I am an enthusiastic and curious learner who is ready to explore the unknown. Like to solve problems. Participated in various events for knowledge enhancing. Presented a paper during the 19th International Conference on Science, Engineering and Technology (ICSET) in Vellore Institute of Technology. Certifications include High Impact Business writing, Artificial Intelligence, Excel Skills from Coursera and strategic thinking from LinkedIn.

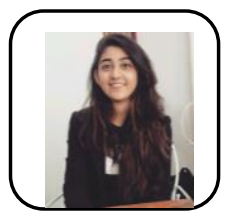

Ankita Wadhwa, (Marketing) Currently employed with BioQuest Solutions Pvt. Ltd. as a Digital Marketing Manager, under the Consulting and Solutioning (Pre-Sales) team. Educational background with a degree in Bachelors of Technology from Indraprastha University, Delhi, followed by Post Graduate Diploma in Marketing Management (Part-time) from NMIMS, Mumbai. Certifications include Fundamentals of Digital Marketing by Google Digital Garage and Advanced Certificate Course in Digital Marketing by Edukart and IAMAI.

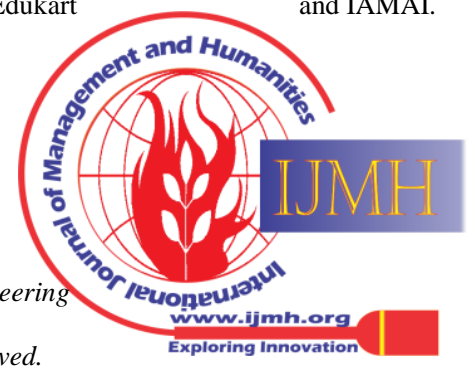




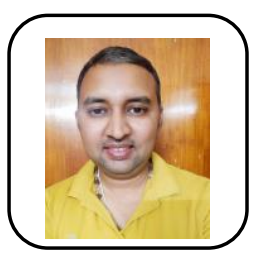

Dr Gramle Amol, Currently employed BioQuest Solutions Pvt. Ltd as Vice President for Consulting and Solutioning (Pre-Sales) team. Educational background with Bachelor of Medicine, Bachelor of Surgery (MBBS) followed by Doctor of Medicine (MD), Clinical Pharmacology and Therapeutics at Rajendra Institute of Medical Sciences and Research Center and Executive Management Degree in Business Analytics and Strategy at Indian Institute of Management, Indore. He has Published research articles in various National and International journals. He is a Life Member in ISPOR-The Professional Society for Health Economics and Outcomes Research and was awarded University Gold Medal- MD Pharmacology in Ranchi University.

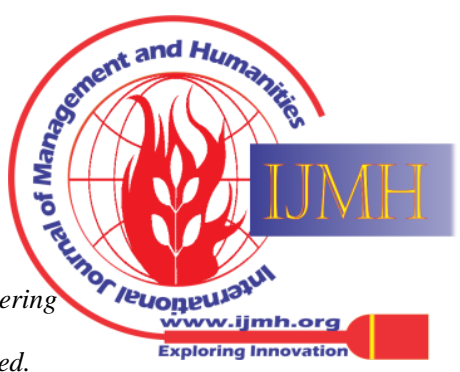

